\title{
Ecological Analysis of the Influence of ACEIs and ARBs on the COVID-19 Prevalence and Death from COVID-19
}

\author{
Wan-Hui Liao1, Maciej Henneberg2,3* \\ ${ }^{1}$ Department of Medical Education, Taipei Veterans General Hospital, Taipei \\ ${ }^{2}$ Institute of Evolutionary Medicine, University of Zurich, Zurich \\ ${ }^{3}$ Biological Anthropology and Comparative Anatomy Unit, University of Adelaide, Adelaide \\ Email: *maciej.henneberg@adelaide.edu.au
}

How to cite this paper: Liao, W.-H. and Henneberg, M. (2021) Ecological Analysis of the Influence of ACEIs and ARBs on the COVID-19 Prevalence and Death from COVID-19. Health, 13, 619-628.

https://doi.org/10.4236/health.2021.135046

Received: April 20, 2021

Accepted: May 28, 2021

Published: May 31, 2021

Copyright $\odot 2021$ by author(s) and Scientific Research Publishing Inc. This work is licensed under the Creative Commons Attribution International License (CC BY 4.0).

http://creativecommons.org/licenses/by/4.0/

\begin{abstract}
Background: Angiotensin-converting enzyme inhibitors (ACEIs) and angiotensin-II receptor blockers (ARBs) have been an arguable risk factor for COVID-19 diseases because they could upregulate Angiotensin Converting Enzyme-2 (ACE2) expression, facilitating SARS-CoV2 entry to the lungs. Several retrospective clinical studies, however, found no such effect. Here, we explore how the use of ACEIs and ARBs links to COVID-19 across all countries of the world. Methods: Data on the availability of ACEIs and ARBs for 200 countries and on the number of cases and number of deaths per country by 28 December 2020 were extracted from WHO and Worldometer website, respectively. Data on life expectancy at age 65 years as a measure of ageing were from WHO and on Gross Domestic Product Per Capita (GDP PPP) and the percentage of urbanization were from the World Bank. Excel and SPSS $\mathrm{v}$ 26 software were used for statistical analyses. Results: In linear regression and logistic conditional regression analysis, GDP correlates with COVID-19 prevalence (rho $=0.66, \mathrm{p}>0.001$ ) and deaths from COVID-19 (rho $=0.55, \mathrm{p}<$ 0.001) while urbanization and life expectancy do not when GDP influence is controlled for. After statistically removing the effects of GDP on the prevalence and mortality from COVID-19, we found that countries without ACEI and ARB availability had lower COVID-19 cases and deaths ( $<<0.02)$. Conclusions: Our study based on the global data contradicts findings of most published clinical studies at regional levels. We found that GDP positively correlates with prevalence of and mortality related to COVID-19. ACEI and ARB use increases COVID-19 infectivity and mortality.
\end{abstract}

\section{Keywords}

COVID-19, RAAS Inhibitors, Ecological Analysis, ACEIs, ARBs 


\section{Introduction}

SARS-CoV-2 causes high fatality in those who have pre-existing condition of hypertension, cardiovascular disease, and diabetes. Because these conditions are recommended by mainstream guidelines to use renin-angiotensin-aldosterone system (RAAS) inhibitors to improve cardiovascular and renal health [1] [2] [3] [4] and that RAAS blockade increases Angiotensin Converting Enzyme-2 (ACE2) expression in the lungs, heart and kidneys [5] [6], there has been a speculation that RAAS inhibitors contribute to COVID-19 infectivity and mortality. ACE2 protein in the respiratory tract serves as the invading target of SARS-CoV-2 virus [7] [8] [9]. ACE2 protein expression in humans is mainly in the respiratory, gastrointestinal tissues and cardio-and-vascular system with remarkably high amounts in the epithelial linings of the pulmonary alveolus and small intestine [10].

Soon after these doubts arose, several retrospective clinical studies at regional scale suggested the otherwise [11] [12] [13]. Along the same lines, several professional societies in early stage of pandemic jointly put forward statements that no solid evidence indicates a contributory role of RAAS inhibitors in COVID-19 disease and that RAAS inhibitors should be continuously used as guideline suggested [14] [15] [16]. However, those clinical studies and also nearly all observational studies published thus far have approached this issue using superiority studies with null hypothesis that "RAAS inhibitors do not increase COVID-19 infectivity and mortality" [11] [12] [13]. This subjects their findings to the type 2 error, where they falsely accepted the null hypothesis which was actually untrue. Given COVID-19 pandemic has entered the third phase and shows no sign to stop anytime soon; we here revisited the association between RAAS inhibitors use and health impacts on COVID-19 among countries using the public data provided by WHO, Worldometer, and the World Bank. We designed a non-inferiority study with a hypothesis that availability of ACEIs and ARBs increases prevalence of COVID-19 and deaths related to COVID-19 to test if RAAS inhibitors do no additional harm to COVID-19 patients.

\section{Methods}

WHO provided data on the availability of RAAS inhibitors-angiotensin-converting enzyme inhibitors (ACEIs) and angiotensin-II receptor blockers (ARBs) in public sector by country for 200 countries in 2020. Data on the number of COVID cases, number of deaths and numbers of tests per country by 28 December 2020 were extracted from the website of Worldometer. This date was chosen to avoid differences between countries in the influences by COVID-19 vaccination. Substantial amounts of vaccination started to be introduced to humans from the early of 2021 according to the website of Our World in Data. In addition, we have obtained data on life expectancy at age 65 years as a measure of ageing from WHO and on Gross Domestic Product Per Capita (GDP PPP) and the percentage of urbanization from the World Bank. The hypothesis tested was that 
availability of ACEIs and ARBs increases prevalence of COVID and deaths related to COVID-19. We have used Excel and SPSS v 26 software to run statistical analyses, specifically descriptive analyses of distribution of variables, comparisons of distributions, non-parametric correlations, linear regressions.

\section{Results}

Due to the obvious variation in health care based on the wealth of a country and its urbanization we have first studied relationships between COVID-19 prevalence and deaths from COVID and GDP, Urbanization and the life expectancy at old age (Table 1, Figure $1 \&$ Figure 2). There was a reasonably strong relationship between GDP and COVID-19 prevalence ( $r$ ho $=0.66, \mathrm{p}>0.01$ ) and deaths from COVID-19 (rho $=0.55, \mathrm{p}<0.01$ ). Relationships of the two COVID variables to Urbanization and life expectancy were similarly strong, but after

Table 1. Non-parametric (Spearman's rho) correlation coefficients among variables studied.

\begin{tabular}{|c|c|c|c|c|c|}
\hline & $\begin{array}{c}\text { Tot } \\
\text { Cases/1M }\end{array}$ & Deaths/1M & $\begin{array}{c}\text { GDP PPP } \\
2015\end{array}$ & $\begin{array}{c}\text { Urban \% } \\
2015\end{array}$ & $\begin{array}{c}\text { Life e65 } \\
(2010-2015)\end{array}$ \\
\hline Tot Cases/1M & 1 & $0.920^{* *}$ & $0.658^{\star *}$ & $0.609^{* *}$ & $0.535^{\star *}$ \\
\hline Deaths/1M & $0.920^{\star *}$ & 1 & $0.550^{* *}$ & $0.520^{* *}$ & $0.510^{\star *}$ \\
\hline GDP PPP 2015 & $0.658^{\star *}$ & $0.550^{\star *}$ & 1 & $0.738^{\star *}$ & $0.767^{\star \star}$ \\
\hline Urban\% 2015 & $0.609^{\star *}$ & $0.520^{\star *}$ & $0.738^{\star *}$ & 1 & $0.645^{\star *}$ \\
\hline Life e65 (2010-2015) & $0.535^{\star *}$ & $0.510^{* *}$ & $0.767^{\star \star}$ & $0.645^{\star *}$ & 1 \\
\hline
\end{tabular}

${ }^{* *}$ Correlation is significant at the 0.01 level (2-tailed).

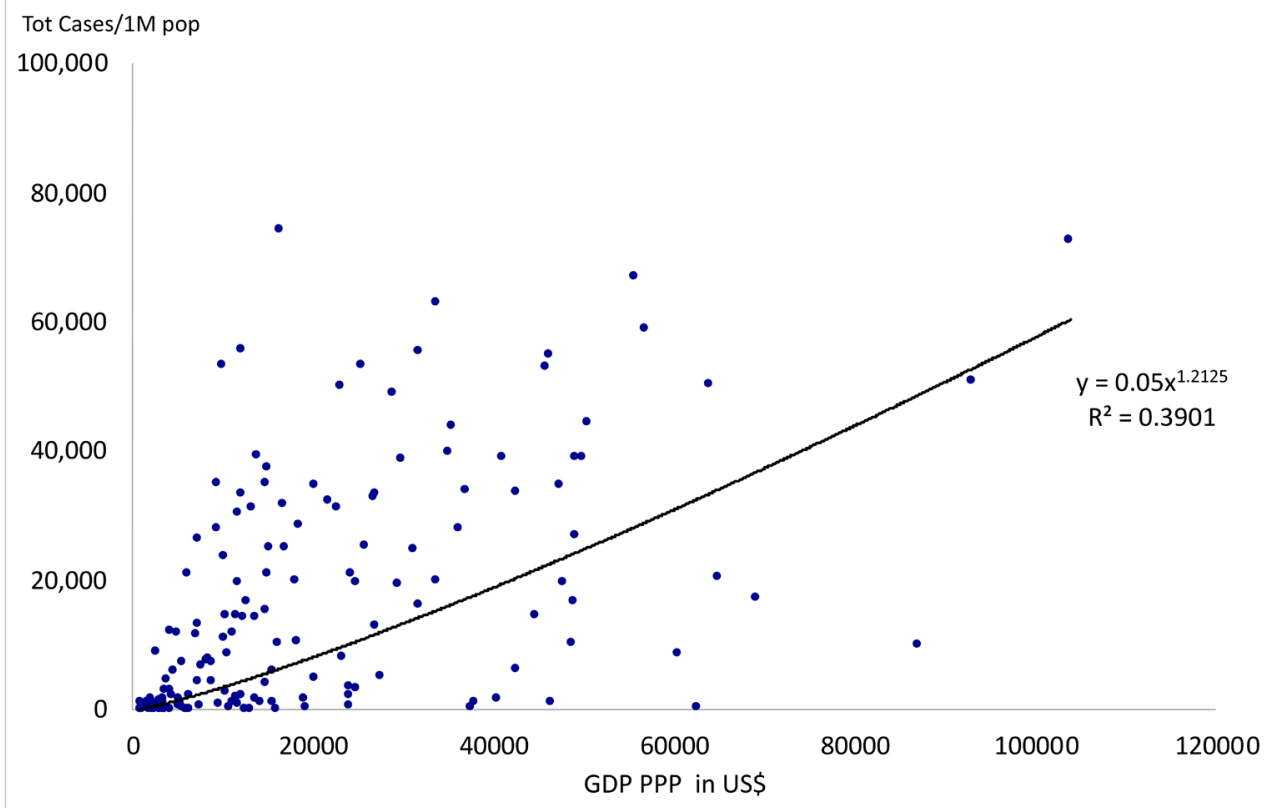

Figure 1. Relationship of the total cases of COVID-19 per 1 million population to the Gross Domestic Product per capita. 


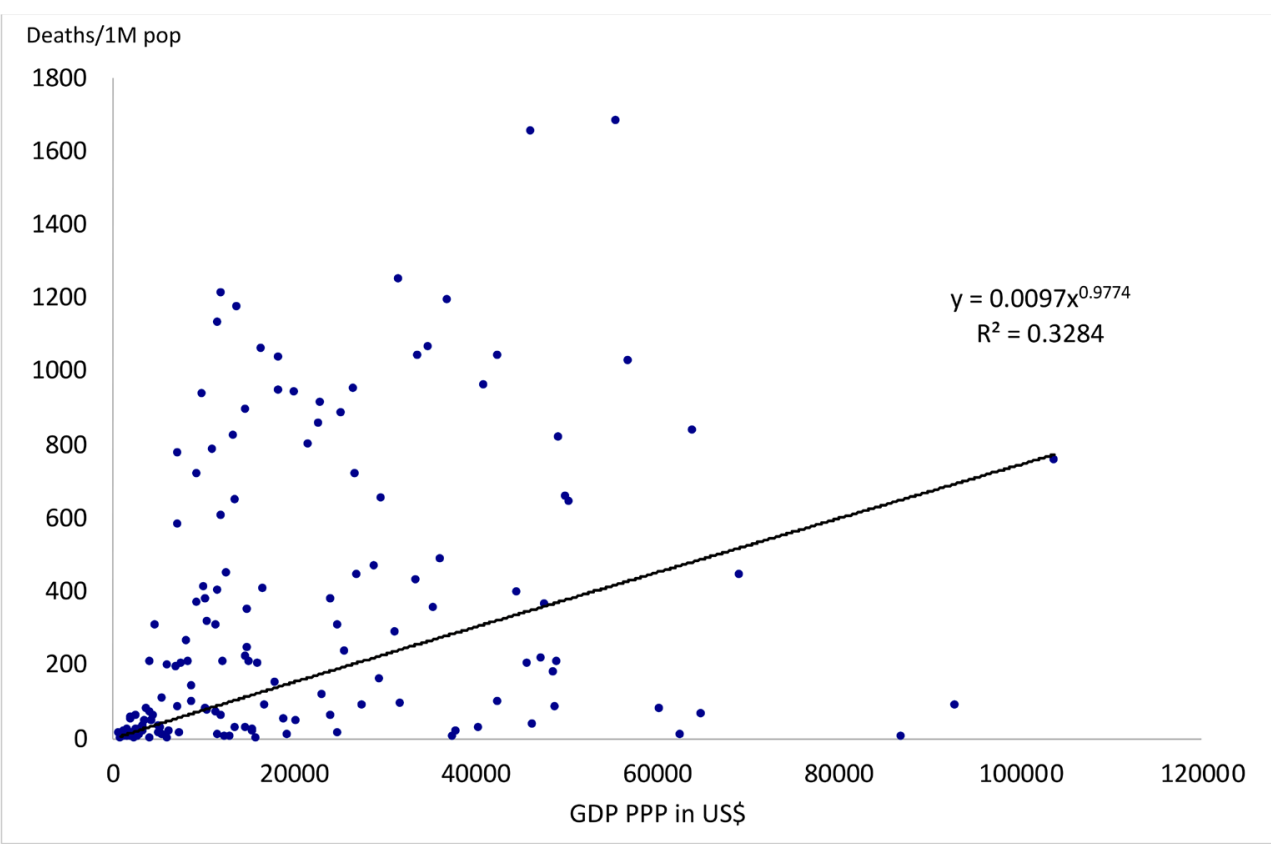

Figure 2. Relationship of the deaths from COVID-19 per 1 million population to the Gross Domestic Product per capita.

influence of GDP was kept statistically constant, they explained less than 5\% of variance each as is obvious from their strong correlations with GDP. Thus their separate influence on COVID has not been studied further.

For further analyses we have transformed prevalence and mortality from COVID to remove effects of GDP. This was done by calculating residuals of the two variables around their power regression lines on GDP (power curves provided the best regression fit-Figure 1 and Figure 2).

Using non-parametric tests of significance (Kolmogorof-Smirnov), distributions and medians and means of GDP standardised numbers of COVID cases and COVID deaths were compared between countries where ACEIs and ARBs were available and those that did not have availability in the public sector.

Clearly, means and medians of COVID cases and deaths due to COVID were much lower in countries without ACEI and ARB availability irrespective whether raw numbers per 1 million people or numbers standardized on GDP were considered (Table 2).

\section{Discussion}

Using the public data provided by WHO, Worldometer, and the World Bank, we found GDP is strongly associated with COVID-19 prevalence $(\mathrm{r}=0.62, \mathrm{p}>$ $0.001)$ and deaths from COVID-19 $(\mathrm{r}=0.57, \mathrm{p}<0.001)$ (Figure 1 and Figure 2). Moreover, prevalence of COVID-19 cases was much lower in countries without ACEI and ARB availability. Death related to COVID-19 disease showed a trend to be lower in countries not using ACEI and ARB. 
Table 2. Statistical parameters of distribution of studied variables. "Corrected for GDP” means residuals of actual values around the regression line on GDP (Figure 1 and Figure 2).

\begin{tabular}{|c|c|c|c|c|c|c|c|c|c|c|c|c|c|c|}
\hline & \multicolumn{2}{|c|}{$\begin{array}{l}\text { cases/1 million } \\
\text { (rough) }\end{array}$} & \multicolumn{2}{|c|}{$\begin{array}{l}\text { Cases } / 1 \text { million } \\
\text { corrected for GDP }\end{array}$} & \multicolumn{2}{|c|}{$\begin{array}{l}\text { Deaths/1 millon } \\
\text { (rough) }\end{array}$} & \multicolumn{2}{|c|}{$\begin{array}{l}\text { Deaths/ } 1 \text { million } \\
\text { Corrected } \\
\text { for GDP }\end{array}$} & \multicolumn{2}{|c|}{$\begin{array}{l}\text { GDP PPP, } \\
2015 \text { US\$, }\end{array}$} & \multicolumn{2}{|c|}{$\begin{array}{c}\text { Urban } \\
\text { population } \\
2015 \%\end{array}$} & \multicolumn{2}{|c|}{$\begin{array}{c}\text { Life expectancy } \\
\text { at age } 65, \\
2010-2015\end{array}$} \\
\hline & no & yes & no & yes & no & yes & no & yes & no & yes & no & yes & no & yes \\
\hline \multicolumn{15}{|c|}{ ACEI available } \\
\hline $\mathrm{N}$ & 30.0 & 150.0 & 31.0 & 150.0 & 26.0 & 140.0 & 28.0 & 141.0 & 29.0 & 146.0 & 32.0 & 153.0 & 32.0 & 149.0 \\
\hline average & 3465.1 & $17,276.9$ & 1224.4 & 8125.5 & 87.9 & 329.0 & 33.5 & 168.8 & 6303.8 & $20,859.5$ & 42.2 & 61.2 & 14.2 & 16.2 \\
\hline median & 465.5 & $10,238.0$ & -61.8 & 1972.0 & 18.0 & 169.0 & -4.7 & 24.3 & 4081.3 & $13,991.8$ & 43.3 & 63.5 & 13.8 & 15.8 \\
\hline St.dev. & 6967.5 & $19,481.6$ & 6439.5 & $17,825.6$ & 177.6 & 384.4 & 158.4 & 371.9 & 7577.3 & $19,625.1$ & 19.9 & 22.5 & 2.3 & 2.5 \\
\hline skewness & 2.5 & 1.3 & 1.6 & 1.4 & 2.6 & 1.2 & 2.3 & 0.9 & 2.7 & 1.6 & 0.5 & -0.2 & 0.9 & 0.2 \\
\hline kurtosis & 10.4 & 1.8 & 5.8 & 5.0 & 10.4 & 0.3 & 7.5 & 0.5 & 10.9 & 3.0 & -0.4 & -1.0 & 0.3 & -1.1 \\
\hline \multicolumn{15}{|c|}{ ARB available } \\
\hline $\mathrm{N}$ & 40.0 & 132.0 & 40.0 & 130.0 & 36.0 & 123.0 & 36.0 & 123.0 & 39.0 & 128.0 & 42.0 & 136.0 & 42.0 & 130.0 \\
\hline average & 4069.2 & $19,095.9$ & 2274.4 & 8493.2 & 94.5 & 364.5 & 55.5 & 174.2 & 5570.7 & $23,414.9$ & 41.0 & 64.9 & 13.8 & 16.7 \\
\hline median & 736.5 & $12,636.5$ & 131.5 & 3585.2 & 19.5 & 203.0 & -0.4 & 36.4 & 3388.7 & $16,204.7$ & 35.0 & 68.0 & 13.7 & 16.5 \\
\hline St.dev. & 7622.1 & $20,021.9$ & 6764.1 & $18,806.7$ & 191.9 & 403.4 & 169.9 & 388.6 & 5269.1 & $19,868.9$ & 21.0 & 21.7 & 1.7 & 2.4 \\
\hline skewness & 2.7 & 1.2 & 2.2 & 1.3 & 3.2 & 1.2 & 3.1 & 0.8 & 1.9 & 1.5 & 0.7 & -0.4 & 1.0 & 0.0 \\
\hline kurtosis & 7.6 & 1.5 & 5.8 & 4.4 & 11.2 & 0.5 & 10.4 & 0.3 & 3.7 & 2.6 & -0.3 & -0.7 & 2.2 & -1.0 \\
\hline
\end{tabular}

Differences between distributions of COVID-19 cases and deaths corrected for GDP in countries with and without ACEI and ARB availability are significant at $\mathrm{p}<0.02$ (Kolmogoroff-Smirnov test SPSSv26). Differences between distributions of other variables in countries with and without ACEi and ARB availability are also highly significant by the same tests, but those are largely a result of economic differences between countries.

Our findings contradict nearly all observational clinical studies approaching the same issue thus far. The main reason should be as follows. Different from previous studies most of which, if not all, were based on regional data and used superiority tests with null hypothesis that RAAS inhibitors do not increase COVID-19 infectivity and mortality, we used the global data and non-inferiority test with null hypothesis of RAAS inhibitors increasing COVID-19 infectivity and mortality. Because the initial concern came from the upregulating effects on ACE2 in respiratory epithelial cells of RAAS inhibitors and thus their contribution to COVID-19 infectivity, having an inferiority test with null hypothesis of RAAS inhibitors increasing COVID-19 infectivity and mortality in the study should be more appropriate. This could avoid the type 2 error where studies falsely accept the untrue hypothesis [17]. Furthermore, our study participants include the whole world and different populations so individual biases balance themselves. GDP is a rough indicator of participation in health systems. The lower the GDP, the less participation in health systems. We have statistically corrected for GDP. So our analysis uses data where GDP is held constant as if there is no difference in participation.

Of course, same as other retrospective observational studies, our work has several limitations. Availability of ACEI and ARB in a country at the time point 
of 2020 only means people there have higher chance to be influenced by ACEI and ARB. It does not reflect directly how ACEI and ARB affect quantitatively a country's COVID-19 infectivity and mortality. The earlier ACEI and ARB were introduced to a country, the longer people there were exposed to ACEI and ARB. Also, the prevalence of hypertension and cardiovascular diseases which mainstream guidelines suggest to use ACEI and ARB vary from country to country and so does patients' medication compliance.

Our finding that GDP levels positively associate with COVID-19 infectivity and mortality was surprising. GDP levels usually highly correlate with how well a country is developed and their investment in preventive care, which includes the healthcare system, sanitation and education [18]. Therefore, countries with higher GDP levels theoretically should be less affected by COVID-19. It may be that better funded health systems diagnosed and reported more COVID-19 cases than systems in poorer countries. This is indicated by the correlation (rho = 0.835 ) between GDP and the number of tests per 1 million population. However, in our analyses we have corrected for this source of error by considering residuals of infections and deaths around regressions on GDP, thus removing at least a part of inequalities of health systems. SARS-CoV-2, same as SARS-CoV and MERS belonging to Betacoronavirus genus, coronaviridae [19] are recognized as important emerging respiratory infectious diseases [20]. Phylogenic studies tracing the origins of COVID-19 suggest that it came from wild animals, including bats and pangolins [21]. Zoonotic infectious diseases involve pathogens that typically circulate unobserved in nature in reservoir animals. For a zoonotic infectious disease to emerge, it typically requires several interacting factors to co-exist, including increased pathogen amounts in the reservoir host communities, pathogen exposure and the within-human factors that affect susceptibility to infections [22]. Global environmental changes, land use for business including deforestation, agriculture and farming expansion certainly could increase SARS-CoV-2 load in reservoir animals, like bats and pangolins and the exposing opportunities for humans to them.

As for factors that increase susceptibility to COVID-19, RAAS inhibitors may play an important role. We previously described how RAAS inhibitors increase the susceptibility to and mortality in SARS-CoV-2 infection by increasing ventilation as respiratory compensation for reduced renal acid excretion and by predisposing the users to develop metabolic acidosis during infection [23]. That work was based on our previous study in aldosterone synthase knockout mice where we found reduced RAAS activity burdens respiration and increased susceptibility to metabolic acidosis [24]. Metabolic acidosis weakens cellular immunity, which is required to effectively defend SARS-CoV-2 infection and other respiratory viruses [25]. Cellular immunity serves to detect and mount the cytotoxic response to remove the virus-infected cells. Also, ACEIs prevent the antigen processing and presentation in virus-infected cells, further compromising cell-mediated immunity [26]. As for the effects of RAAS inhibitors on ACE-2 
levels, they are rather complex to study. ACE2 levels in plasma and tissue are subject to change by age, sex, medications, diseases and different disease courses. Plasma ACE2 comes from the cell surface by metalloproteinase ADAM17-dependent cleavage of the membrane-bound ectodomain of ACE2 [27]. Males, older subjects ( $>55$ years old), insulin resistance stage are all associated with higher circulating ACE2 proteins levels [28]. Diabetic nephropathy is correlated with a reduced ACE2 abundance in the kidney [29] [30] but with an increased urine ACE2 levels. On the other hand, inconsistent findings on ACE2 protein expression in the heart between failing heart and non-failing heart were reported [31] [32]. Recently, it was reported that heart failure patients on RAAS inhibitors and those not on RAAS inhibitors do not differ in plasms ACE2 levels [33]. As these cardiovascular, metabolic and renal issues are frequently co-present and that ACE2 levels are likely changing dynamically along diseases courses, it may be difficult to dissect the influence of RAAS inhibitors on ACE2 expression in humans who have multiple comorbidities and on many medications. Moreover, the amount of ACE2 in respiratory epithelial lining is of particular importance in this regard, but, it requires the collection of human lung biopsy specimens which imposes another layer of technical challenge to the study.

\section{Conclusion}

Previous clinical studies on SARS and Middle East Respiratory Syndrome also revealed medicated hypertension as a factor predicting high mortality in infected patients [34] [35]. As three coronavirus outbreaks have already emerged in humans since 2000 being temporally associated with hypertension medications gaining popularity [36] [37], the possibility of RAAS inhibitors contributing to COVID-19 should be carefully assessed. In parallel, several randomized clinical trials (RCT) are underway assessing influences of RAAS inhibitors in COVID-19 disease outcome. Cohen et al. reported that discontinuation of RAAS inhibitors in patients who have been using RAAS inhibitors prior to hospitalization does not influence the disease outcome. This result certainly is reassuring to medical communities and to patients who are on RAAS inhibitors but keep in mind that this is a small trial, where only a total of 152 patients were included [38]. Given that the COVID-19 pandemic is already entering the third waves, showing no signs to cease soon and that there are still many people taking RAAS inhibitors to control cardiovascular risks, role of RAAS inhibitors in COVID-19 diseases should be carefully assessed and recommendations to continuously using RAAS inhibitors during COVID-19 may require reconsiderations.

\section{Conflicts of Interest}

The authors declare no conflicts of interest regarding the publication of this paper.

\section{References}

[1] American Diabetes Association (2002) Standards of Medical Care for Patients with 
Diabetes Mellitus. Diabetes Care, 25, 213-229.

https://doi.org/10.2337/diacare.25.1.213

[2] American Diabetes Association (2020) Standards of Medical Care in Diabetes-2020 Abridged for Primary Care Providers. Clinical Diabetes, 38, 10-38.

https://doi.org/10.2337/cd20-as01

[3] Yancy, C.W., et al. (2013) 2013 ACCF/AHA Guideline for the Management of Heart Failure: A Report of the American College of Cardiology Foundation/American Heart Association Task Force on Practice Guidelines. Journal of the American College of Cardiology, 62, e147-e239.

[4] Whelton, P.K., et al. (2018) 2017 ACC/AHA/AAPA/ABC/ACPM/AGS/APhA/ASH/ ASPC/NMA/PCNA Guideline for the Prevention, Detection, Evaluation, and Management of High Blood Pressure in Adults: A Report of the American College of Cardiology/American Heart Association Task Force on Clinical Practice Guidelines. Hypertension, 71, e13-e115. https://doi.org/10.1161/HYP.0000000000000076

[5] Li, X.C., Zhang, J. and Zhuo, J.L. (2017) The Vasoprotective Axes of the Renin-Angiotensin System: Physiological Relevance and Therapeutic Implications in Cardiovascular, Hypertensive and Kidney Diseases. Pharmacological Research, 125, 21-38. https://doi.org/10.1016/j.phrs.2017.06.005

[6] Yuan, Y.M., et al. (2015) Activation of Renin-Angiotensin-Aldosterone System (RAAS) in the Lung of Smoking-Induced Pulmonary Arterial Hypertension (PAH) Rats. Journal of the Renin-Angiotensin-Aldosterone System, 16, 249-253. https://doi.org/10.1177/1470320315576256

[7] Yan, R., et al. (2020) Structural Basis for the Recognition of SARS-CoV-2 by Full-Length Human ACE2. Science, 367, 1444-1448. https://doi.org/10.1126/science.abb2762

[8] Jia, H.P., et al. (2005) ACE2 Receptor Expression and Severe Acute Respiratory Syndrome Coronavirus Infection Depend on Differentiation of Human Airway Epithelia. Journal of Virology, 79, 14614-14621. https://doi.org/10.1128/JVI.79.23.14614-14621.2005

[9] Wrapp, D., et al. (2020) Cryo-EM Structure of the 2019-nCoV Spike in the Prefusion Conformation. https://doi.org/10.1101/2020.02.11.944462

[10] Hamming, I., et al. (2004) Tissue Distribution of ACE2 Protein, the Functional Receptor for SARS Coronavirus. A First Step in Understanding SARS Pathogenesis. The Journal of Pathology, 203, 631-637. https://doi.org/10.1002/path.1570

[11] de Abajo, F.J., et al. (2020) Use of Renin-Angiotensin-Aldosterone System Inhibitors and Risk of COVID-19 Requiring Admission to Hospital: A Case-Population Study. The Lancet, 395, 1705-1714. https://doi.org/10.1016/S0140-6736(20)31030-8

[12] Mancia, G., et al. (2020) Renin-Angiotensin-Aldosterone System Blockers and the Risk of Covid-19. The New England Journal of Medicine, 382, 2431-2440. https://doi.org/10.1056/NEJMoa2006923

[13] Reynolds, H.R., et al. (2020) Renin-Angiotensin-Aldosterone System Inhibitors and Risk of Covid-19. The New England Journal of Medicine, 382, 2441-2448. https://doi.org/10.1056/NEJMoa2008975

[14] ESC Council on Hypertension (2020) Position Statement of the ESC Council on Hypertension on ACE-Inhibitors and Angiotensin Receptor Blockers.

[15] European Medicines Agency (EMA) (2020) Latest Data Support Continued Use of ACE Inhibitors and ARB Medicines during COVID-19 Pandemic.

[16] American College of Cardiology (2020) A.H.A.a.H.F.S.o.A., HFSA/ACC/AHA State- 
ment Addresses Concerns Re: Using RAAS Antagonists in COVID-19.

[17] Akobeng, A.K. (2016) Understanding Type I and Type II Errors, Statistical Power and Sample Size. Acta Paediatrica, 105, 605-609. https://doi.org/10.1111/apa.13384

[18] O'Donnell, O. (2007) Access to Health Care in Developing Countries: Breaking down Demand Side Barriers. Cadernos de Saúde Pública, 23, 2820-2834. https://doi.org/10.1590/S0102-311X2007001200003

[19] Zhu, Z., et al. (2020) From SARS and MERS to COVID-19: A Brief Summary and Comparison of Severe Acute Respiratory Infections Caused by Three Highly Pathogenic Human Coronaviruses. Respiratory Research, 21, 224. https://doi.org/10.1186/s12931-020-01479-w

[20] Bradley, B.T. and Bryan, A. (2019) Emerging Respiratory Infections: The Infectious Disease Pathology of SARS, MERS, Pandemic Influenza, and Legionella. Seminars in Diagnostic Pathology, 36, 152-159. https://doi.org/10.1053/j.semdp.2019.04.006

[21] Lam, T.T., et al. (2020) Identifying SARS-CoV-2-Related Coronaviruses in Malayan Pangolins. Nature, 583, 282-285. https://doi.org/10.1038/s41586-020-2169-0

[22] Gibb, R., et al. (2020) Ecosystem Perspectives Are Needed to Manage Zoonotic Risks in a Changing Climate. BMJ, 371, m3389. https://doi.org/10.1136/bmj.m3389

[23] Liao, W.H., Yang, G.G. and Henneberg, M. (2020) The Renin-Angiotensin-Aldosterone System Inhibitors in COVID-19: From Acidosis to Ventilation and Immunity. Swiss Medical Weekly, 150, w20444. https://doi.org/10.4414/smw.2020.20444

[24] Liao, W.H., et al. (2018) Aldosterone Deficiency in Mice Burdens Respiration and Accentuates Diet-Induced Hyperinsulinemia and Obesity. JCI Insight, 3, e99015. https://doi.org/10.1172/jci.insight.99015

[25] Schmidt, M.E., et al. (2018) Memory CD8 T Cells Mediate Severe Immunopathology Following Respiratory Syncytial Virus Infection. PLoS Pathogens, 14, e1006810. https://doi.org/10.1371/journal.ppat.1006810

[26] Bernstein, K.E., et al. (2018) Angiotensin-Converting Enzyme in Innate and Adaptive Immunity. Nature Reviews Nephrology, 14, 325-336.

https://doi.org/10.1038/nrneph.2018.15

[27] Iwata, M., Silva Enciso, J.E. and Greenberg, B.H. (2009) Selective and Specific Regulation of Ectodomain Shedding of Angiotensin-Converting Enzyme 2 by Tumor Necrosis Factor Alpha-Converting Enzyme. American Journal of Physiology-Cell Physiology, 297, C1318-C1329. https://doi.org/10.1152/ajpcell.00036.2009

[28] Kuznetsova, T. and Cauwenberghs, N. (2020) Determinants of Circulating Angiotensin-Converting Enzyme 2 Protein Levels in the General Population. European Journal of Internal Medicine, 84, 104-105. https://doi.org/10.1016/j.ejim.2020.10.012

[29] Mizuiri, S., et al. (2008) Expression of ACE and ACE2 in Individuals with Diabetic Kidney Disease and Healthy Controls. The American Journal of Kidney Diseases, 51, 613-623. https://doi.org/10.1053/j.ajkd.2007.11.022

[30] Reich, H.N., et al. (2008) Decreased Glomerular and Tubular Expression of ACE2 in Patients with Type 2 Diabetes and Kidney Disease. Kidney International, 74, 1610-1616. https://doi.org/10.1038/ki.2008.497

[31] Donoghue, M., et al. (2000) A Novel Angiotensin-Converting Enzyme-Related Carboxypeptidase (ACE2) Converts Angiotensin I to Angiotensin 1-9. Circulation Research, 87, e1-e9. https://doi.org/10.1161/01.RES.87.5.e1

[32] Tikellis, C. and Thomas, M.C. (2012) Angiotensin-Converting Enzyme 2 (ACE2) Is a Key Modulator of the Renin Angiotensin System in Health and Disease. Interna- 
tional Journal of Peptides, 2012, Article ID: 256294. https://doi.org/10.1155/2012/256294

[33] Sama, I.E., et al. (2020) Circulating Plasma Concentrations of Angiotensin-Converting Enzyme 2 in Men and Women with Heart Failure and Effects of Renin-AngiotensinAldosterone Inhibitors. European Heart Journal, 41, 1810-1817.

https://doi.org/10.1093/eurheartj/ehaa373

[34] Morra, M.E., et al. (2018) Clinical Outcomes of Current Medical Approaches for Middle East Respiratory Syndrome: A Systematic Review and Meta-Analysis. Reviews in Medical Virology, 28, e1977. https://doi.org/10.1002/rmv.1977

[35] Matsuyama, R., et al. (2016) Clinical Determinants of the Severity of Middle East Respiratory Syndrome (MERS): A Systematic Review and Meta-Analysis. BMC Public Health, 16, 1203. https://doi.org/10.1186/s12889-016-3881-4

[36] Burnier, M. and Egan, B.M. (2019) Adherence in Hypertension. Circulation Research, 124, 1124-1140. https://doi.org/10.1161/CIRCRESAHA.118.313220

[37] Egan, B.M., et al. (2014) Hypertension in the United States, 1999 to 2012: Progress toward Healthy People 2020 Goals. Circulation, 130, 1692-1699.

https://doi.org/10.1161/CIRCULATIONAHA.114.010676

[38] Cohen, J.B., et al. (2021) Continuation versus Discontinuation of Renin-Angiotensin System Inhibitors in Patients Admitted to Hospital with COVID-19: A Prospective, Randomised, Open-Label Trial. The Lancet Respiratory Medicine, 9, 275-284. 